\title{
The Evaluation of Policy Coherence for Development
}

\author{
ROBERT PICCIOTTO \\ King's College, London
}

The promotion of human welfare in the zones of turmoil and transition can no longer be evaluated simply by examining the degree to which aid programs and projects achieve their relevant objectives efficiently. With globalization, the rules of the game that govern the international economy have become pivotal. Yet, the policies that govern trade, investment, migration, knowledge flows, environmental protection and human security have escaped systematic evaluation. To help ascertain the impact of rich countries' policies on the economic and social prospects of poor countries, evaluators must broaden the scope of their assessments and examine the combined impact of aid and non-aid policies on poor countries. Following an overview of policy coherence for development (PCD) monitoring and evaluation concepts and activities, the article explores evaluation options designed to account for the development impact of rich countries' policies and to encourage greater synergy among rich countries' policies in support of global poverty reduction.

KEYWORDS: development evaluation; evaluability; global public policy; monitoring; policy

This article addresses the potential role of evaluation in enhancing the coherence of rich countries' policies from the perspective of poor countries. In development as in other public endeavors, evaluation matters to public welfare since opinion drives policy, wrong opinions (or opinions driven by special interests) induce bad policies, and evaluation has the potential of enriching opinion with knowledge and enhancing the accountability of decision-makers for results. Towards these ends, evaluation collects relevant evidence, identifies suitable standards of value, uses valid methods of analysis, and disseminates evaluation findings to policymakers and policy-takers. But evaluation works best when the object subjected to evaluation is properly defined. What then is the meaning of policy coherence for development? 


\section{Policy Coherence for Development}

An authoritative definition is found in a Ministerial Statement of the Organization of Economic Cooperation and Development (OECD, 2002). It states that policy coherence for development aims to

... enhance understanding of the development dimensions of member country policies and their impacts on developing countries ... (It) should consider trade-offs and potential synergies across such areas as trade, investment, agriculture, health, education, the environment and development cooperation, to encourage greater policy coherence in support of the internationally agreed development goals.

This functional definition needs elaboration for evaluation purposes. Thus, Fukusaku and Hirata define policy coherence for development (PCD) as the consistency of policy objectives and instruments applied by OECD countries individually or collectively in the light of their combined effects on developing countries' (Fukusaku and Hirata, 1995). This formulation points to the main sources of possible incoherence and suggests that PCD comprises four distinct elements:

(i) Internal coherence: the consistency between goals and objectives, modalities and protocols of a single policy or program carried out by an OECD government in support of development (e.g. aid).

(ii) Intra-country coherence: the consistency among several aid and non-aid policies of an OECD government in terms of their combined contribution to development.

(iii) Inter-country coherence: the consistency of aid and non-aid policies across several OECD countries in terms of their aggregate contribution to development.

(iv) Donor-recipient coherence: the consistency of policies adopted by rich countries collectively and poor countries individually or collectively to achieve shared development objectives.

While these four aspects of coherence are governed through distinct decisionmaking structures, they are closely interrelated. In the real world of policy implementation, decisions that affect coherence along one dimension have implications for coherence in one or more of the other three dimensions. The traditional focus of development evaluation has been on type (i) coherence - the alignment of means with goals in development assistance.

Yet, unless development evaluation reaches out well beyond aid, the main defining feature of PCD (i.e. the identification of trade-offs and synergies across policy domains towards achieving development objectives) will not benefit from objective assessment. Conversely, evaluation of PCD would allow decisionmakers to learn from experience and accelerate the adjustment of policies in directions that will improve the welfare of over four-fifths of the world's population that live in middle- and low-income countries. 


\section{The Rationale of PCD}

Articulating the rationale for PCD helps in the determination of evaluation priorities. The increased interdependence of societies and nations has vastly increased the benefits of policy convergence among development partners. Fueled by demography and the new communications technologies, economies and societies have become inextricably interconnected.

OECD countries rely on developing countries for a third of their export sales and one half of their oil consumption. Developing countries depend on OECD countries for over 60 percent of their trade and about half of their commodity imports. Mutual benefits flow from aid, trade, investment, and migration. With globalization, new economic opportunities (in trade, investment, and knowledge transfers) have emerged. But so have a host of 'problems without passports'.

The recurrent financial crises, the terrorist outrages of $9 / 11$ and 3/11 and the SARS and avian influenza epidemics illustrate the risks to peace and prosperity associated with lack of international cooperation in an interdependent world. Unless major progress towards policy coherence for development is achieved, most developing countries will not achieve the millennium development goals (MDGs) solemnly endorsed by all United Nations members at the turn of the century.

The baseline for all the MDGs is 1990. Most MDGs have been set for 2015. More than halfway to the deadline, the implementation record is mixed. Reduced incidence of malnutrition among children, improved maternal health conditions, and increased primary school enrollment, especially for girls, represent notable achievements. But the current rate of progress is too slow to achieve most of the goals. Only a third of developing countries are on track to meet them. Regional differences are striking. The zones most in need of development (most of Africa and large parts of South Asia) are lagging. At current growth rates, East Asia alone is likely to reach the agreed poverty reduction goal of halving the number of people living on less than one dollar a day (Vandemoortele, 2003).

Working to achieve type (i) coherence (coherence between the ends and means of aid) has been a traditional focus of Development Assistance Committee activities since its inception. This has involved extensive work on aid effectiveness at the project and program level. It has also involved advocacy work to encourage member countries to raise the volume of aid. Both objectives remain highly relevant. First, aid quality needs to be improved. Administrative costs absorb 6-7 percent of aid flows. Tied aid costs about $\$ 5$ billion a year in needless markups for goods and services. Much of the technical assistance funded by aid has low value. The poorest countries get less than 30 percent of all aid and the share of aid allocated to basic social services is less than half the level recommended by the United Nations (20 percent).

Second, current aid levels are insufficient to achieve agreed goals. The goal of 0.7 percent of GDP for aid enshrined in numerous UN conferences has only been reached by a handful of countries. Even if the commitments announced at the United Nations Financing for Development Conference in Monterrey are met and aid grows by 31 percent in real terms by 2006 (about $\$ 16$ billion), aid volumes 


\section{Evaluation 11(3)}

will remain inadequate. The 2001 report on the United Nations high-level panel on Financing for Development (Zedillo Report) estimates that an extra $\$ 50$ billion in development aid per year would be required to meet the MDGs, that an additional \$8-9 billion would be required for basic humanitarian assistance, and a further $\$ 20$ billion to address 'global public goods' issues (such as the environment) in a more satisfactory manner. ${ }^{1}$

But the type (ii) and (iii) coherence goals that are at the heart of PCD go well beyond aid and require a 'whole of government' approach. Ultimately, they aim to make the global economic order a level playing field. ${ }^{2}$ Box 1 gives examples of type (ii) incoherence issues that require policy adjustment in combination with compensation schemes.

\section{Box 1. Some Examples of Potential Policy Incoherence (Type ii)}

Agricultural policies in OECD countries sustain a cherished way of life but they benefit very few citizens - mostly prosperous farmers and agro-industrial firms. They protect domestic supplies of crop and livestock products that can be produced at a fraction of the cost in developing countries. Tariffs and subsidies impose heavy costs on consumers and taxpayers in OECD countries. They undermine equitable growth in the developing world, where the majority of the poor live.

The highest tariffs on industrial goods imposed by OECD countries affect products that are critical to the economic wellbeing of developing countries - steel, textiles, clothing, and leather. Relatively low-income consumers in OECD countries consume these products.

The protection of intellectual property rights under WTO rules promotes research and innovation but it also restricts access to essential drugs and other knowledgeintensive products and services in poor countries.

Immigration restrictions are imposed for cultural reasons and to sustain domestic wages but they restrict increased remittances to developing countries and aggravate labor shortages in OECD countries faced by an unprecedented demographic transition.

Fishing subsidies of OECD countries absorb \$15-20 billion a year, benefit large companies more than poor fishing communities, and deplete fish populations on which poor countries' coastal fisheries depend.

Industrialized countries (home to 20 percent of the world's population) account for 63 percent of carbon dioxide that has accumulated in the atmosphere since 1900. Global warming will impose heavy costs on developing countries. Small island economies are especially vulnerable.

A recent United States law that mandates counter-terrorism protection measures in ships and ports imposes heavy investment costs on poor countries that lack budgetary resources for basic social programs.

\section{PCD and the European Union}

The policy coherence concept is rooted in Article 130U of the Maastricht Treaty of 7 February 1992 that sets out development objectives for the Community (sustainable development, integration in the global economy, poverty eradication, democracy, the rule of law, and respect for human rights). Article 130V (the 
coherence article) states explicitly: "the Community shall take account of the objectives referred to in Article $130 \mathrm{U}$ in the policies that it implements which are likely to affect developing countries'. ${ }^{3}$ Though weakly worded, the provision is clearly pro-development and marks the first formal acknowledgment of PCD in a multilateral context.

To be sure, the Yaounde agreements of 1964 and 1969 had already laid stress on the complete equality of the 18 African countries with the six EEC contracting partners. Article 11 presaged the coherence principle by mandating consultation with the associated states in the design of the Common Agricultural Policy. On the other hand, the $\mathrm{C}$ word only became current following a European Commission decision of May 1994 that reduced beef export subsidies that had been shown to hurt livestock farmers in the Sahel: it is therefore necessary to take measures to end the serious incoherence that exists between the agricultural policy and the development policy of the Community'.

Revealingly, the principle of coherence is connected to two other operating principles: coordination and complementarity (thus completing the trilogy of 'the triple C' [Schrijver, 2001]). While coordination supports coherence, complementarity constrains it. Thus, Article 130U (Article 177 in the Treaty of Amsterdam) stipulates that the development assistance policies of the Community shall be complementary to the policies pursued by member states and also that the Community and the member states shall comply with the commitments they have made and take account of the objectives they have approved under the aegis of the United Nations and other international organizations.

Community activities do not prejudice the competence of European states to participate in international bodies and to conclude international agreements (Article 181). This confirms that complementarity holds sway over the other two $\mathrm{Cs}$ - coherence and coordination. Furthermore, the principle of subsidiarity (i.e. the affirmation of diversity and the preference given to local and national decision-making over community decision-making provided basic European agreements, policies, and values are respected) could be viewed as a further constraint on type (ii) and (iii) coherence. Furthermore, the treaty does not mandate implementation of PCD. Nor does it specify modalities for PCD. All in all, there remains considerable ambiguity and room for maneuver in PCD application by EU member states.

\section{PCD and the United Nations}

The United Nations has made effective use of its convening power to promote PCD. At the Millennium Summit held in New York in 2000 - the largest gathering of heads of state ever held - all United Nations member states approved a historic declaration. It laid out specific goals to reduce human misery, enhance social development, and promote environmental regeneration (UNGA, 2001). Two years later, in March 2002, at the United Nations Conference on Financing for Development held in Monterrey (Mexico), a global development compact was forged and verifiable indicators of development progress were agreed (the Millennium Development Goals or MDGs). 


\section{Evaluation 11(3)}

For the first time in development history, general principles of development cooperation were universally endorsed. They match the adoption of improved policies and good governance by developing countries with the provision of more and better aid, debt reduction, and the creation of a fairer and more open financial and trading system. This mutual accountability framework supports development objectives of unrivaled legitimacy. The global agreement to track human progress through 18 targets and 48 indicators is unprecedented.

The MDGs embody universal aspirations (poverty reduction, social development, environmental regeneration) and sum up with great economy the outcomes of numerous international conferences. They have helped to strengthen development coalitions and have articulated a compelling rationale for aid to a largely skeptical public. To amplify their impact, the UNDP has launched a global public information effort (the Millennium Campaign) and provided intellectual leadership in promoting global public goods as a new rationale for aid (Kaul et al., 1999).

Of course, the intricacies of equitable, sustainable, inclusive development cannot be accurately summarized in the MDG scorecard. Income poverty reduction is critical but so are the other freedoms that constitute human development. Reduced child mortality is important but so is adult health status. Increased school enrollment matters but it does not guarantee learning. Nor do the MDGs invariably reflect country priorities. Concern has been expressed about their neglect of macroeconomic management, private-sector development, infrastructure development, etc.

Most of all, the mutual accountability framework of the MDGs has not been backed up by binding government undertakings. For improved coherence in development to be reflected in results, agreement on general principles is not enough. Nor is the rhetoric of results helpful without a clear articulation of the programmatic foundations of policy. To be sure, the UN Secretary General's report to the Preparatory Committee of the Monterrey Conference included 87 recommendations. But the final communiqué of the Conference, negotiated in advance, did not include action plans. Each country was left free to set its own course and formulate its own benchmarks.

The MDG framework demands more of developing countries than it does of developed countries. Only the eighth millennium development goal addresses the responsibilities of OECD countries and it does so with less precision than the other seven goals. Most of the agreed indicators (35 out of 48) point south. Vast resources have been mobilized to monitor progress in developing country policies and programs. No similar effort has been put in place to monitor the improvement of policies adopted by rich countries.

\section{PCD and the International Financial Institutions}

The international financial institutions (IFIs) have rallied behind the MDGs. They are assisting the UNDP in monitoring progress towards the MDGs. By the time the MDGs emerged, the leadership of the World Bank had adopted operational emphases that largely coincide with the human development tenets of the 
United Nations system. As a result, relationships between the IFIs, the United Nations, and the bilateral aid donors have improved, a prerequisite of type (iii) coherence.

In turn, the convergence of development objectives among donors has opened the way to an innovation in development assistance - the Poverty Reduction Strategy Paper (PRSP) process sponsored by the World Bank and the IMF. It holds the promise of greatly facilitating donor-recipient relations. Despite teething problems ${ }^{4}$ the PRSP process has secured broad support across the development community. PRSP guidelines reflect the principles of comprehensive development, country ownership, broad-based partnerships, and results orientation in line with the millennium declaration and the DAC principles of effective aid (DAC, 1992).

Since the reliance on a limited number of indicators at the global level may not be responsive to country aspirations, the structure of PRSPs has been kept flexible while broadly consistent with the MDG logic. Domestically owned, the PRS process is designed to yield a common framework for programming, monitoring, and evaluation of domestic public expenditures. It also provides a template for aid coordination that has the legitimacy of country ownership. Tailor-made to each country situation, the PRS process has the potential of improving type (iii) coherence; and of acting as a two-way transmission belt between the global goals and national planning and budgeting systems - type (iv) coherence. The UN programming cycle is being reshaped to connect to it.

Unfortunately, the overwhelming focus of the PRSP initiative has been on the assessment and the monitoring of developing country performance, with no attention paid to the impact of developed country policies on the likelihood of achieving global results. Except in Tanzania (which has created an Independent Monitoring Group to keep track of aid quality), the IFIs have not provided the 'policy space' or the capacity-building support required for developing-country governments to carry out their own evaluations of aid effectiveness, let alone the overall policy performance of OECD countries from a development perspective. Nor has much progress been made in incorporating rigorous PCD assessments within the regular reporting processes of the International Monetary Fund.

\section{PCD and NGOs}

As part of the grand debate on globalization, civil society organizations have played a leading role in sensitizing public opinion with respect to the development incoherence of OECD policies. They have also helped to mobilize political support for specific policy reforms. In 1994, an NGO campaign decried the impact of European beef export subsidies on West Africa's rural welfare. In 1996, NGOs lobbied against a fisheries policy that allocated fishing rights and subsidies without regard to the impact on the coastal fisheries of developing countries. A year later a proposed lift of the ban on cocoa butter alternatives faced strong opposition from development NGOs.

Similarly, the Highly Indebted Poor Countries (HIPC) debt relief initiative would not have been born without the Jubilee campaign. More recently, the 


\section{Evaluation 11(3)}

international trade agreement on generic drugs in the run up to the Cancun meeting would not have materialized without the skillful work of major advocacy NGOs. No reform of OECD agricultural trade and subsidy policies is likely without continued, evidence-based civil society activism.

Equally, with respect to foreign direct investment, NGOs are likely to remain instrumental in sustaining the momentum of the corporate social responsibility movement and the harmonization of social and environmental safeguard policies by international development and commercial credit and guarantee agencies. These are important elements of the PCD agenda.

Therefore, a proactive stance of NGOs vis-a-vis the private sector and developing country governments could be a critical contribution of NGOs to PCD. This will require less ideological posturing and greater concentration on the adoption of improved business norms and standards through advocacy campaigns and independent verification.

\section{PCD and the OECD}

Despite the manifold initiatives of the development community summarized above, the mutual accountability framework of the development system remains unbalanced. Progress in promoting type (ii), type (iii), and type (iv) coherence (emphasized by the OECD ministers) has lagged behind type (i) coherence. Most of the efforts devoted to policy coherence for development have been allocated to improved targeting, management, and evaluation of aid agency programs and projects. By contrast, issues of consistency that cut across policies, countries, and agencies - type (ii) and (iii) coherence - have been neglected. The resulting evaluation gaps with respect to type (iv) coherence have contributed to an ideological gridlock in globalization debates.

According to the July 2003 OECD Policy Brief: 'greater development coherence in OECD governments' policy stances will allow the benefits of globalization to be more equitably distributed and shared' (OECD Observer, 2003). The horizontal program of policy coherence characterizes PCD as involving the systematic promotion of mutually reinforcing policy actions across government departments and agencies creating synergies towards achieving the agreed objectives'. It embraces a broad agenda (trade, agriculture, governance of development aid, investment and business climate, migration, environmental sustainability, and technological development).

PCD in the OECD goes beyond integrating the development dimension into the work of other policy communities. It seeks to integrate the findings of those communities into the development cooperation policies of the OECD. Of course, politicians cannot be expected to abandon domestic concerns for the sake of PCD. But as they are presented with the development consequences of their decisions, they may think twice before adopting policies that may have deleterious impacts on poor countries. ${ }^{5}$ Thus, the framers of the PCD horizontal initiative expect that concrete evidence and compelling analyses will help promote win-win outcomes, avoid flagrant policy contradictions, minimize the probability of negative impacts on development, and amplify the voice of the global poor in 
the corridors of power, especially when new policy initiatives are debated, designed, and approved.

This is why the PCD cross-cutting initiative of the OECD is so critical. It aims at ensuring that each OECD country pursues policies that support or at least do not undermine the development process in poor countries. Building political support for PCD among stakeholders so that OECD countries initiate adjustment of a wide range of policies that affect developing countries would help accelerate progress towards the MDGs. For the OECD Secretariat, this will entail delivery of analytical underpinnings for informed policy-making, providing a platform for policy dialogue and monitoring of PCD performance.

In particular, as proposed by the DAC Chair (DAC, 2003), beyond the traditional focus on making development assistance more effective - type (i) coherence - the OECD will need to tool up to promote the creation of analytical capacity on coherence issues, support research on the impact of rich countries' policies on poor countries, commission 'just in time' coherence analyses, conduct political economy assessments geared to strengthening public support for increased aid and other development friendly policy reforms, and strengthen PCD monitoring and evaluation. The latter is critical to the credibility of the horizontal program.

As currently framed and resourced, the OECD peer group review system does not deliver rigorous assessment of PCD performance at the country level because it is not governed by clear and uniform standards connected to explicit PCD objectives. It does not respond to uniform standards and remains heavily dependent on the degree to which individual OECD governments willingly contribute information and analyses on PCD issues. This means that it works best for countries that are fully committed to PCD.

\section{PCD Monitoring}

The United Nations Development Program (UNDP) has completed 44 country reports that track $\mathrm{MDG}$ progress. It has done so in close consultation with partners in the UN Development Group, other UN partners, the World Bank, the IMF, and the OECD, and regional groupings and experts. The UN Department of Economic and Social Affairs is reporting on progress towards the goals at the aggregate level.

In parallel, the World Bank has launched a new series of Global Monitoring Reports addressed to the Development Committee of World Bank/IMF Governors. These reports deal with the policies and actions for achieving the MDGs and related outcomes. But they are heavily focused on poor countries' performance and have only begun to address the progress made by developed countries in meeting their MDG obligations. They are doing so in aggregate terms and they are selective: they cover quality of macro-financial policies supportive of growth and stable capital flows, the quantity and quality of aid, debt relief, trade policies, and global public goods.

In February 2004, a round table on 'managing for development results' sponsored by the multilateral banks and the Development Assistance Committee of 


\section{Evaluation 11(3)}

OECD endorsed core principles for results-based management and committed to focus their operational programs on country results, harmonized reporting and capacity-building in monitoring and evaluation and national statistics. But here again, the focus of the proposed monitoring efforts has remained on the development effectiveness of country-level development assistance programs and projects. No attention to the rules of the game of the global economy is envisaged.

\section{Rating PCD Performance}

Given the limited focus of official development agencies on type (ii) coherence issues, it is fortunate that development think tanks (including the OECD's own Development Centre) have begun to look into PCD. In particular, the Center for Global Development has published a Commitment to Development Index (CDI) that aims to shift public attention from the policies of the south to the policies of the north (Birdsall and Naim, 2003). The CDI is innovative and helpful since it helps to rectify the mental construct according to which the shortfalls being witnessed in the progress towards the $\mathrm{MDGs}^{6}$ can be attributed solely to ineffective aid, poor governance, or weak policies in developing countries.

The new scorecard seeks to generate incentives for 'laggards' in the donor community to clean up their policy act. The publication of the index in Foreign Policy on a regular basis is meant to raise public awareness of the responsibilities borne by the industrialized democracies for the state of the world. The logic of CDI is straightforward: the policy performance of individual OECD countries is rated along six dimensions, using plausible quality indicators for which reasonably accurate data are available.

For example, the aid component of the index adjusts gross aid flows to take account of principal repayments, administrative costs, technical assistance costs, and tied aid. It addresses aid quality through a selectivity index that favors aid directed to poor countries and penalizes aid allocated to countries with weak governance. The second edition of the index captures aid fragmentation that contributes to the inefficiency of aid delivery. ${ }^{7}$ But it does not incorporate adjustments for the share of aid directed to basic human needs ${ }^{8}$ or the degree of support provided through budget support, pool funding, and other flexible forms of aid.

The focus on tariffs and the limited range of non-tariff measures covered by the index has yet to capture the extensive restrictions on trade in services - an area of growing interest and value to developing countries. The bundling of data on non-trade barriers masks the restrictive impact that frivolous anti-dumping actions, complex regulations, and perverse enforcement standards have on trade flows. The index also fails to take account of the impact of preferential arrangements and the predilection for bilateral trade agreements displayed by the European Union and the United States.

The CDI uses rich countries' contributions to United Nations peacekeeping operations as a proxy for the quality of security policies pursued by rich countries. This is misleading considering the massive arms trade flows originating in the same 
countries. ${ }^{9}$ The index does not capture the enormous waste of resources associated with excessive military expenditures (O'Hanlon, 2002). Finally, the CDI uses the same weights for all six dimensions. Yet enough is known to make educated estimates of the relative importance of the index components (just as the CGD framers did when constructing individual ratings for each of the components). Research models ${ }^{10}$ estimate the welfare benefits of trade liberalization for agriculture and manufactures to range anywhere from $\$ 108$ billion to $\$ 760$ billion for developing countries. Models including liberalization of trade in services raise the benefits by a factor of 4-5 (World Bank, 2002).

Similarly, it makes little sense for the index to give the same weight to aid (which contributed about $\$ 49$ billion in net official financing to developing countries in 2002) as to private investment (which contributed about $\$ 163$ billion) or to remittances from migrants to developing countries (estimated to be at least $\$ 80$ billion) (World Bank, 2003). To be approximately right is better than to be precisely wrong. Using weights that capture estimates of relative magnitudes of impact would improve the index and significantly change the country rankings.

In time, CGD expects to carry out impact research assessments that may provide reliable assessment of weights and illuminate policy choices. ${ }^{11}$ To increase the legitimacy of the CDI and its ownership in developed and developing countries alike, an independent oversight mechanism focused on the validity of the methods and of the data that underlie CDI construction will have to be considered.

\section{Evaluability Assessments}

When politicians construct a working consensus among diverse interest groups they often settle for second- or third-best solutions that strike a balance among conflicting goals. Thus, L. Alan Winters (2000) has observed that in the real world, the 'here' in policy coherence is hard to find since, more often than not, policy has multiple dimensions and uncertainty prevails about the links between policy levers and policy impacts. In such circumstances, policy coherence is necessarily elusive. Equally elusive is the avoidance of self-contradiction and minimization of policy change over time (another meaning of coherence). Unexpected events, third-party intervention, or shifts in opinion inevitably induce shifts in policy stances.

'Evaluability' (Wholey, 2002) analysis can help delineate the limits of coherence through assessment of decision protocols and encouragement of implementation planning. Only then can the ambiguity regarding the objective one seeks to cohere about (e.g. a specific poverty reduction target) be lifted. There may be no agreement among stakeholders about the means to the goal due to divergent interests, conflicting worldviews, or simply a lack of knowledge about what works and does not work. Ambiguity about plans may even be deliberate and obfuscation about objectives may be a political expedient. This can be established through evaluability assessments.

For example, type (iv) incoherence issues may be uncovered, e.g. when developing-country policy-makers are concerned about the unintended results of 


\section{Evaluation 11(3)}

type (iii) coherence in terms of a 'ganging up' effect that can facilitate the imposition of inappropriate policy standards on aid recipients. At the UNCTAD X Conference, the Indian Minister of Commerce warned: 'we should be careful that in the name of coherence we do not create a networking behemoth which puts pressure on developing countries through cross-conditionality' (Global Policy Forum, 2003). Thus, policy coherence has a dark side when it is achieved without democratic debate and involves coercion.

\section{The Accountability Dimension}

While perfect policy coherence is not feasible, pervasive incoherence undermines public trust, creates uncertainty, contributes to social tensions, and creates waste. Coherence in public affairs, while hard to achieve in practice, is an ideal well worth striving for. Expert evaluation is needed to ascertain whether the levels of coherence actually achieved are close to the feasible level.

Clarity of objectives and rigorous analytical underpinnings for alternative courses of action are critical to the performance assessments that underlie accountability. Hence, appropriate measures of coherence are needed to test the quality of public policy and programs. In a democracy, citizens need not tolerate unnecessary incoherence, i.e. decisions that are inefficient from a social welfare perspective in circumstances where win-win outcomes are demonstrably feasible. Necessary incoherence, on the other hand, is acceptable if it is the outcome of a principled negotiation among diverse interest groups and leads to aggregate improvements in public welfare.

It is useful to distinguish between unintended incoherence that may occur because of factors outside the control of those in authority and intended incoherence that may have been accepted to achieve acceptable outcomes (e.g. where trade-offs are made to accommodate conflicting goals). Of course, intended incoherence may also result not from principled compromises on the directions in which a policy pulls or from uncertainty regarding the links between policy means and goals but simply because of incompetence, corruption, or capture by vested interests.

From an accountability perspective, the bottom line is that policy-makers who choose unnecessary incoherence either unintendedly, e.g. if they are uninformed and/or incompetent or intendedly, e.g. when they decide to favor the few at the expense of the many, should be censured. During the Watergate hearings, Senator Howard Baker asked: 'What did he know? And when did he know it?' Both questions arise every time a politician makes a decision that directly or indirectly impacts on the public welfare. ${ }^{12}$ Consistency between what a decision-maker knows (or ought to know) and what he/she decides to do is an integral part of coherent decision-making.

Thus, when pursued with tolerance and discernment and backed up by expert evaluation, policy coherence is a legitimate benchmark for judging policy-making and its implementation. Public accountability means congruence between what is known about how to achieve the common welfare and what those in authority choose to do to achieve it. In this way, evaluation of policy coherence helps 
to enhance the public welfare in two ways. First, it encourages the set up of good governance arrangements. Second, it favors the selection of principled leaders who make decisions in the public interest.

In sum, good government implies transparency in decision-making, evidencebased policy formulation, and independent monitoring and evaluation to assess how the major agents involved in policy-making and implementation fulfill their reciprocal obligations: consider the alternatives open to them, reach the decisions they do, and follow up with appropriate implementation arrangements. Through evaluation, one can draw critical distinctions between intended vs unintended incoherence and necessary vs unnecessary incoherence - both when policies are designed and when they are put into practice.

\section{The Social Learning Dimension}

Analytically, the coherence concept is a meaningful evaluation test when it addresses a policy goal that is unambiguously defined. On first examination, this does not seem an excessive requirement. After all, dictionaries define coherence as 'the action of sticking together' or 'the quality of being logically integrated, consistent and intelligible'. The term evokes logic, consistency, and constancy of purpose. In physics, the term refers to the force by which molecules are held together, the 'constant phase relationship' of waves or the viscosity of a substance. In philosophy, coherence theory holds that 'the truth of a proposition consists in the coherence of that proposition with all other true propositions'. These are very precise concepts.

By contrast, in the social sciences that evaluation relies on, the term is new and untested (Hoebink, 2001). On the one hand, absolute policy coherence implies that the preference functions of diverse groups can be aggregated without ambiguity. On the other hand, economic theory demonstrates the exact opposite: majority rule leads to outcomes that depend less on preferences than on agenda setting and the sequencing of votes (Arrow, 1963). Kenneth Arrow's 'impossibility theorem' concludes that, under plausible assumptions, only absolute and competent dictatorships operating in stable environments can achieve full and consistent policy coherence. Unstable voting coalitions, vote trading and logrolling, and the need to partition decision-making in order to achieve a stable equilibrium are ultimately due to this logical predicament.

Dilemmas of collective action are most intractable within large groups (due to free riding). Hence, the rationale of splitting decision-making among separate committees or government departments that enjoy primary jurisdiction over specialized domains. But breaking complex issues into manageable segments encourages a 'silo' approach to decision-making whereby coherence within a group is either undermined or secured at the expense of incoherence among groups. Strong leadership and judicious decision-making protocols are needed to minimize the risks of inconsistency. This is why the evaluation of policy coherence requires an assessment of the degree to which a 'whole of government' approach is actually being followed.

Ultimately, evaluation of policy coherence implies an assessment of the quality 


\section{Evaluation 11(3)}

of the social learning environment. A consistent approach to decision-making requires shared values, transparent information links among stakeholders, as well as transparency in the relationship between specialized units and sovereign decision-making bodies. In principle, once coherent policy goals have been set, clear outcome indicators are selected and the right choices made among alternative courses of action. In practice, choices are constrained by inadequate knowledge, time pressure, and limited analytical capacity.

Policy is not implementation. In the real world, a variety of obstacles may stand in the way of achieving coherent results. The causal links between stages in the results chain that connects inputs with outputs, outcomes and impact, are rarely known with precision. In such circumstances, optimization emerges only if the information and the analytical resources required to achieve it are free. ${ }^{13}$ Conversely, according to the 'rational ignorance' doctrine, apparently incoherent behavior is explained by information asymmetries, data processing costs, and reluctance to take risks. Equally, coherence of outcomes cannot be guaranteed ex-post even when it has been secured ex-ante at the policy design stage.

This foray into the economics of coherence confirms that the limits of coherence need to be factored into PCD evaluations. Ideally, policy coherence requires precise delineation of policy goals, objective assessment of options, and effective management of the sundry programs associated with policy executions. In practice, because of the imponderables of implementation, monitoring must complement evaluation in order to facilitate mid-course corrections.

While monitoring facilitates management for results, it does not relate results to the behavior of individual actors (attribution) and therefore does not facilitate learning. Nor does monitoring establish whether the most appropriate course of action has been selected. These issues are privileged domains for evaluation. Thus both monitoring and evaluation matter to social learning. Without monitoring it is not possible to track performance. Without evaluation, a simplistic view of coherence may prevail and the wrong results may materialize. What then are the evaluation options for PCD?

\section{Evaluation Options}

Ongoing PCD evaluation initiatives are still few and have yet to bear fruit. This is because today's development business is narrowly focused on the design of projects and programs within developing countries. It fails to give explicit and targeted consideration to the global enabling environment within which these activities are implemented. This 'path dependence' will have to be broken to improve the accuracy of development evaluations and help make globalization work for all - the poor as well as the rich. In particular, the orthodox and positivist approach to development evaluation will have to be reconsidered to give more emphasis to the higher plane of global policy and to make greater use of the participatory and empowerment approaches to evaluation. Qualitative approaches and triangulation techniques pioneered outside the development evaluation profession will have to be imported into the mainstream of PCD evaluation. 
The implications of the necessary shift in priorities for evaluation have yet to be explored. The mutual accountability framework of the Monterrey consensus is a good place to start. The new compact delineates shared development objectives embedded in the MDGs. It defines the reciprocal obligations of development partners: the responsibility for poverty reduction policies and governance improvements lies with poor countries while reform of the global 'rules of the game' (MDG8) is assigned to rich countries. For OECD evaluators, this new fiduciary architecture for global development implies a shift in evaluation priorities from traditional project and country program evaluations towards the global plane.

Currently, development evaluation relates development outcomes to the design of aid programs and projects and the domestic policy and institutional environment. They treat OECD countries' policies as given and 'exogenous'. PCD evaluation would shift the focus of analysis towards global public policies and make them endogenous. This is not a trivial change. It will add considerable complexity to the evaluation process. The enormity of the challenge may explain the limited progress made in tackling it. But a start must be made. Breaking the problem into manageable components can help. Several evaluation options must be considered and pursued in parallel. There is no magic bullet.

First, just as development evaluation units currently arrange for systematic reviews of individual projects and country programs, PCD evaluation could tackle systematic independent multi-donor evaluations of international collaborative multi-country development programs currently in place to deliver global public goods, share knowledge across countries, or set business and/or professional standards. The number of such programs has increased exponentially in recent years and they have largely escaped the scrutiny of evaluators even though serious questions are being raised about their governance, their efficiency, and the results achieved.

Second, PCD evaluation could gradually take on vertical multi-country reviews of individual policies (aid, trade, migration, etc.) on a regional or global basis. Such reviews would require assessments of impacts of recent or proposed policy shifts on economic and social conditions in representative countries, both developed and developing, together with the compensatory arrangements proposed for losers in the adjustment process. Priority should be given to policy vectors that are the subject of new international agreements, well ahead of their formal negotiations.

Third, part of the PCD evaluation challenge could be met by systematic assessments of the PCD aspects of national policies on a horizontal basis. This could consist of self-evaluation (viz. the approach being piloted by some Nordic donors and the Netherlands). In order to ensure symmetry with the PRSP system in place within poor countries, it could be combined with independent evaluations and oversight (guidelines, advisory support, etc.), for example, by the OECD Secretariat and/or the Development Committee.

Fourth, a privileged unit of account for PCD evaluations might be a sample of representative developing countries within which the development impact of specific reforms in OECD policies (e.g. increase in quality or quantity of aid, 


\section{Evaluation 11(3)}

gradual removal of cotton subsidies, reduced immigration restrictions, etc.) would be tracked and recommendations made both to OECD and to the countries concerned in order to enhance the synergy of policy reforms and to improve the design of aid programs.

Fifth, considering that the OECD proposes to target such policy areas as investment, business climate, technology, and environmental sustainability as well as sectors such as agriculture and health where the private sector plays a major role, PCD evaluations might include independent assessments of the impact of regulatory regimes and standards (whether voluntary or compulsory) on developing countries.

Sixth, it might be useful to produce and/or sponsor or commission an annual progress report on PCD that would build on the CDI index but enhance its legitimacy and evaluative content through formal participation by governments, the private sector and civil society.

\section{Evaluation Methods}

When connected to organizational performance mechanisms and backed by independence features, evaluation can be used to strengthen accountability ${ }^{14}$ and to promote realism in PCD design and implementation. It can facilitate societal learning by inducing policy-makers to face up to the actual impact of policy designs and operational practices.

The tool kit of the evaluation profession is well stocked to deal with PCD. This is especially the case when the objects selected for review are 'evaluable' (Wholey, 2002) and the resources allocated are commensurate to the task. For example, program evaluation theory is well adapted to the assessment of global collaborative programs.

Similarly, meta-evaluation methods combined with theory-based evaluation techniques (Weiss, 1998) constitute evaluative instruments of choice for multicountry PCD evaluations of individual policy vectors. Global PRSPs ${ }^{15}$ and country impact evaluations would require the deployment of case-study and policy research tools. The battery of 'new public management' evaluation tools can be used for tackling assessments of regulatory regimes and corporate social responsibility standards.

The objectives-based approach (Hanna and Picciotto, 2002) is well adapted to PCD evaluations. Typically, development evaluators compare results (outputs, outcomes, and impacts) to the goals set at the outset of an aid intervention. This provides a useful link to internal management mechanisms. Equally, development evaluators have ample experience with the evaluation of partnerships that lie at the core of the PCD evaluations challenge (Liebenthal et al., 2004).

PCD evaluation would add a twist to the traditional approach of development evaluators by bringing out in a transparent fashion the balance of interests that are actually served by the policies, programs, and projects of development assistance agencies. From a methodological standpoint, the injection of PCD would force development evaluators to unbundle program objectives and impacts among development partners and assess the balance of costs and benefits among 
them. This would help improve the accuracy and credibility of assessments and strengthen the participatory dimension of the evaluation process.

Equally, through evaluation, new policies aiming at minimizing the negative externalities of programs and projects would be emulated. Just as the social and environmental assessments are used as part of the appraisal of industrial and infrastructure projects, new 'PCD impact assessments' are emerging when major policies are screened by the European Union. In time, this could lead to the adoption of safeguard PCD standards based on the Hippocratic principle ('first, do no harm'). Implementation of such policies would be informed by impact assessments. The policies would also provide a legitimate framework for independent verification mechanisms.

Another potential extension of development evaluation practice to PCD management would involve the systematic use of process evaluations to address PCD aspects. Such evaluations would address the relevance, efficacy, and efficiency of PCD institutional arrangements at national, regional, or global level. They would examine (i) coordination arrangements and participatory mechanisms; (ii) the quality of analytical capacity; (iii) the guidelines for policy-making; (iv) the standards for assessing tradeoffs among primary policy objectives and developing country interests; (iv) the monitoring and evaluation arrangements.

\section{Evaluation Governance}

Methodological rigor is not sufficient to ensure credibility of evaluations. The design of evaluation governance to guarantee independence, objectivity, and 'value added' is of critical importance since verifiable truth can only be ascertained through iterative processes that recognize the limits of rationality and contestability challenges that take account of the power of vested interests. Checks and balances in evaluation are critical to the evaluation of PCD. Organizational design models that have proven effective in national and multilateral settings for development evaluation may not be applicable to PCD evaluation. Whereas development evaluation typically operates within a sovereign government or organization, the achievement of policy coherence from a development perspective involves reviews of actions taken by several sovereign nations and autonomous organizations.

Hence, there is a need to adapt the principles that underlie the design of sound development evaluation structures to the higher plane of PCD evaluation. First, the credibility of the evaluation function hinges on an arm's-length relationship with line managers and policy-makers. Second, its usefulness depends on its capacity to influence policy formulation and decision-making (independence is not isolation). Third, its integrity requires compliance with the same principles of accountability, learning, and transparency that it is designed to promote.

These principles mean that the most promising approaches are those that combine self-evaluation with independent evaluation. Contestability of selfevaluation findings by independent evaluation and oversight of self-evaluation standards by independent evaluation constitute basic features of sound PCD evaluation governance. 


\section{Evaluation 11(3)}

The diversity of evaluation approaches needed to capture the many facets of PCD precludes a single organizational model. But some of the lessons drawn from experience in joint development evaluations are likely to have relevance for PCD evaluations: (i) the major stakeholders should be involved in the design of evaluation objectives, standards, and methods; (ii) their respective responsibilities and obligations should be agreed at the outset; (iii) the evaluation team should be endowed with considerable autonomy; (iv) adequate skills and resources should be provided for the conduct of evaluation and the dissemination of its results.

Last but not least, credible PCD evaluation will imply a serious effort to involve developing countries in the process. This will call for a major commitment to evaluation capacity development from donors. It will also call for evaluation funding and governance arrangements that give substantive control of a major segment of the PCD agenda to developing country governments, organizations, and citizens. Just as development projects and programs executed by poor countries have benefited from evaluations by donor organizations controlled by rich countries over the years, it would make sense for rich country policies that affect poor countries to benefit from evaluations carried by evaluation organizations controlled by poor countries.

\section{Conclusion}

In sum, tackling the PCD evaluation challenge will require a judicious mix of self-evaluation and independent evaluation. A full range of evaluation instruments will have to be deployed. PCD evaluation will have to guide PCD monitoring. Tailor-made, eclectic evaluation methods will have to be selected. Close interaction between policy-makers and evaluators will have to be ensured. Numerous and complex as these demands may be, they will have to be met. Unless they are, development evaluation will gradually lose its relevance in the volatile, fractured, and interconnected global system of the 21 st century.

\section{Notes}

The article is based on a paper commissioned by the Organization for Economic Cooperation and Development for a conference held in Paris on 18-19 May 2004.

1. United Nations high-level international intergovernmental consideration of financing for development (the 'Zedillo Report'), Agenda item 101, General Assembly 55th Session, 26 June 2001 (http://www.un.org/esa/ffd/a55-1000.pdf).

2. Debt reduction policies remain too restrictive: official development assistance to least developed countries has shrunk from 12 percent to 7.5 percent of their GDP while debt service is about 3 percent of GDP.

3. The EC Council of Ministers of Development Cooperation Nov. 1992 declaration also recognized the linkage between development cooperation policy and other Community policies and urged the Commission to consider how impact assessments might be carried out more systematically, especially with regard to new proposals.

4. While the PRSP process requires involvement of the private sector, civil society organizations and parliamentarians, there are concerns among voluntary organizations 


\section{Picciotto: The Evaluation of Policy Coherence for Development}

on the extent to which review of the PRSP by the IFI boards inhibits genuine participation.

5. For example, the EU Ministers announced on 22 March 2004, that they would cut off aid to countries not cooperating in the fight against terrorism (International Herald Tribune, 23 March 2004).

6. ActionAid's MDG report card at half term is: $\mathrm{D}$ for poverty reduction; $\mathrm{C}$ for education; $\mathrm{C}$ for gender; $\mathrm{F}$ for child mortality; $\mathrm{D}$ for maternal health; $\mathrm{F}$ for diseases and $\mathrm{E}$ for the environment (ActionAid, 2002).

7. The Development Gateway now includes records about 340,000 projects. Tanzania alone has nearly 7,000 projects funded by 80 donor organizations.

8. The international community has endorsed an allocation of 20 percent while the current share is about 11 percent.

9. Conventional arms used in developing countries' conflicts contribute to about 300,000 deaths annually.

10. The high end of the range is drawn from Dessus et al. (1999). It is based on a dynamic model with productivity growth. The low end of the range is by Anderson et al. (2000) It is based on a static steady state model.

11. A research proposal for impact research underwritten by the Global Development Network following workshops sponsored by the Global Policy Project, the OECD Development Research Centre and the Centre for Global Development is under preparation.

12. Recent controversies about the intelligence available prior to $9 / 11$ (crying wolf too late?) and the Iraq war (crying wolf too early?) illustrate this principle.

13. This explains why policy research and evaluation are public goods that tend to be under-financed.

14. Unfortunately, most development organizations are not equipped with genuinely independent evaluation organizations and they have tended to use results-based management (RBM) more to enhance planning than to increase accountability. With the exception of the World Bank and some regional development banks, RBM systems used in development agencies have lacked independent ratings of professional quality and institutional performance in their scorecards.

15. Just as poor countries are currently mandated to prepare strategies of poverty reduction, rich countries would prepare strategies outlining their proposed contributions to global poverty reduction (through aid and other policy instruments).

\section{References}

ActionAid (2002) Halfway There? The G8 and the Millennium Development Goals in 2002. London: ActionAid.

Anderson, K. et al. (2000) 'Potential Gains from Trade Reform in the New Millennium', Paper presented to the Third Annual Conference on Global Economic Analysis, Monash University.

Arrow, K. J. (1963) Social Choice and Individual Values. New York: Wiley.

Birdsall, N. and M. Naim (2003) 'Ranking the Rich', Foreign Policy (May/June). http://www.foreignpolicy.com.

Dessus, S., K. Fukasaku and R. Safadi (1999) Multilateral Tariff Liberalization and the Developing Countries, OECD Development Centre Brief, 18. Paris: OECD.

Development Assistance Committee (1992) Principles of Effective Aid. Paris: OECD.

Development Assistance Committee (2003) Development Co-operation Report: Chapter 1: Overview by the DAC Chair. Paris: OECD, 23 Oct. DAC/2003/24. 


\section{Evaluation 11(3)}

Fukusaku, K. and A. Hirata (1995) 'The OECD and ASEAN: Changing Economic Linkages and the Challenge of Policy Coherence', in Fukusaku, Plummer and Tan (eds), OECD and the ASEAN Economies: the Challenge of Policy Coherence. OECD, Paris.

Global Policy Forum (2003) 'Harmonization and Coherence: White Knights or Trojan Horses?', Bretton Woods Project, Aug. (http://www.globalpolicy.org/socecon/bwi-wto/ wbank $/ 2003 / 08 \mathrm{knights.htm).}$

Hanna, N. and R. Picciotto (2002) Making Development Work, World Bank Series on Evaluation and Development, 4. New Brunswick, NJ: Transaction.

Hoebink, P. (2001) 'Evaluating Maastricht's Triple C: The C of Coherence', Working Document, Policy and Evaluation Department, Ministry of Foreign Affairs, Dec. The Hague.

Kaul, I., I. Grunberg and M. A. Stern (1999) Global Public Goods, International Cooperation in the 21st Century, United Nations Development Program. Oxford: Oxford University Press.

Liebenthal, A., O. N. Feinstein and G. K. Ingram (2004) Evaluation and Development: The Partnership Dimension, World Bank Series on Evaluation and Development, 6. New Brunswick, NJ: Transaction.

OECD (2002) Action for a Shared Development Agenda, Ministerial Statement. Paris: OECD.

OECD Observer (2003) 'Policy Coherence: Vital for Global Development', Policy Brief. Paris: OECD.

O'Hanlon, M. (2002) Defense Spending and the Index. Washington, DC: Center for Global Development.

Schrijver, N. (2001) "“Triple C" From the Perspective of International Law and Organization', Working Document, Policy and Operations Evaluation Department, Ministry of Foreign Affairs, The Hague.

United Nations, General Assembly (2001) Road Map towards the Implementation of the United Nations Millennium Declaration, Report of the Secretary-General (A/56/326). New York: UNGA.

Vandemoortele, J. (2003) 'Are the MDGs Feasible? United Nations Development Programme', Development Policy Journal 3 (April).

Weiss, C. H. (1998) Evaluation, 2nd edn. Upper Saddle River, NJ: Prentice-Hall.

Wholey, J. S. (2002) Evaluability Assessment: Improving Evaluation, Management and Performance. Washington, DC: General Accounting Office of the United States and University of Southern California.

Winters, L. A. (2000) 'Coherence with No "Here": WTO Co-operation with the World Bank and the IMF', Nov. 2001, draft paper originally prepared for the CEPR/ECARES World Bank Conference on the World Trading System Post Seattle, 14-15 July (available at: www.tulane.edu/ dnelson/PEReformConf/Winters.pdf).

World Bank (2002) Global Economic Prospects and the Developing Countries 2002. Washington, DC: World Bank.

World Bank (2003) Global Development Finance. Washington, DC: World Bank.

ROBERT PICCIOTTO, former Director General, Operations Evaluation at the World Bank, is Visiting Professor at King's College, London. Please address correspondence to him at: 2 I Palace Gate, Flat 5, London W8 5LS, UK.

[email: R.Picciotto@btinternet.com] 